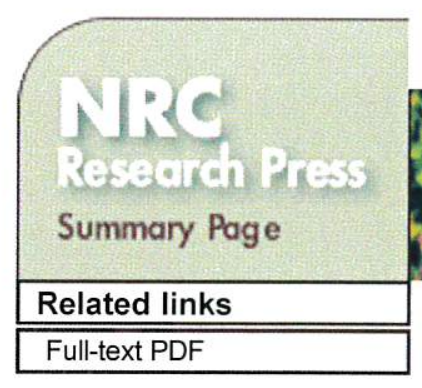

Return to table of contents | Journal Home

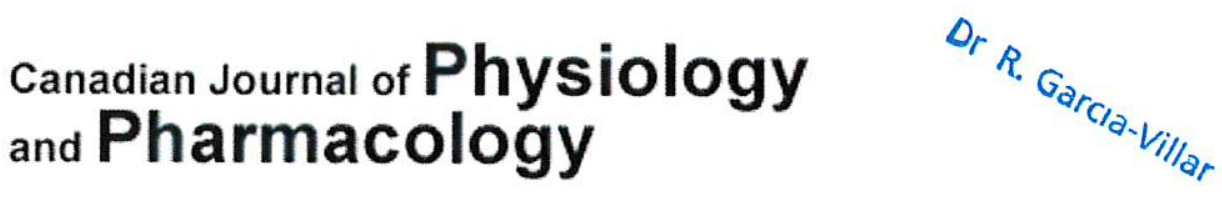

Canadian access to full text made available through the Depository Services Program

Can. J. Physiol.

Pharmacol. 81(9): 920-927 (2003) | doi:10.1139/y03-080 | (C) 2003 NRC

Canada

\title{
Colitis induced by proteinase-activated receptor-2 agonists is mediated by a neurogenic mechanism
}

\section{Cathy Nguyen, Anne-Marie Coelho, Eileen Grady, Steven J. Compton, John L. Wallace, Morley D. Hollenberg, Nicolas Cenac, Rafael Garcia-Villar, Lionel Bueno, Martin Steinhoff, Nigel W. Bunnett, and Nathalie Vergnolle}

\begin{abstract}
Proteinase-activated receptor-2 $\left(\mathrm{PAR}_{2}\right)$ activation induces colonic inflammation by an unknown mechanism. We hypothesized that $\mathrm{PAR}_{2}$ agonists administered intracolonically in mice induce inflammation via a neurogenic mechanism. Pretreatment of mice with neurokinin-1 and calcitonin-gene-related peptide (CGRP) receptor antagonists or with capsaicin showed attenuated $\mathrm{PAR}_{2}$-agonist-induced colitis.

Immunohistochemistry demonstrated a differential expression of a marker for the type-1 CGRP receptor during the time course of $\mathrm{PAR}_{2}$-agonist-induced colitis, further suggesting a role for CGRP. We conclude that $\mathrm{PAR}_{2}$-agonist-induced intestinal inflammation involves the release of neuropeptides, which by acting on their receptors cause inflammation. These results implicate $\mathrm{PAR}_{2}$ as an important mediator of intestinal neurogenic inflammation.
\end{abstract}

Key words: trypsin, proteinase-activated receptor-2, colitis, neurogenic inflammation, substance $\mathrm{P}$, neurokinin-1 receptors, calcitonin-gene-related peptide.

Résumé : L'activation du proteinase-activated receptor-2 $\left(\mathrm{PAR}_{2}\right)$ dans le colon provoque une réaction inflammatoire dont le méchanisme est encore inconnu. Nous avons émi l'hypothèse que l'administration intracolique d'agonistes pour le récepteur $\mathrm{PAR}_{2}$ provoque un méchanisme inflammatoire de type neurogène. Des souris ayant reçues un pré-traitement à la capsaicine ou un antagoniste des récepteurs neurokinine-1 ou gene-related peptide (CGRP), n'ont developpé qu'une réponse inflammatoire très attenuées en réponse à l'injection intracolique d'agonistes pour le récepteur $\mathrm{PAR}_{2}$. De plus, des études 
d'immunohistochimie ont montré qu'un marqueur pour le récepteur CGRP était exprimé différemment au cours de la réaction inflammatoire provoquée par l'agoniste $\mathrm{PAR}_{2}$. Nous pouvons conclure que la réaction inflammatoire du colon en réponse aux agonistes $\mathrm{PAR}_{2}$ implique la libération de neuropeptides qui, en agissant sur leurs récepteurs (neurokinine-1 et CGRP), provoquent une réaction inflammatoire. Ces résultats suggèrent un rôle important pour le récepteur $\mathrm{PAR}_{2}$ dans les phénomènes inflammatoire de type neurogène, particulièrement au niveau de l'intestin.

Mots clés : trypsine, proteinase-activated receptor-2, colite, inflammation neurogène, substance $P$, recepteur à la neurokinine 1 , calcitonin-gene-related peptide. 


\section{Proteinase-Activated Receptor 2 agonists-induced colitis is mediated by a neurogenic mechanism}

Cathy Nguyen ${ }^{a}$, Anne-Marie Coelho ${ }^{b}$, Eileen Grady ${ }^{b}$, John L., Wallace ${ }^{a}$, Morley D. Hollenberg ${ }^{a}$, Nicolas Cenac ${ }^{c}$, Rafael Garcia-Villar ${ }^{c}$, Lionel Bueno ${ }^{c}$, Martin Steinhoff ${ }^{d}$, Nigel W. Bunnett ${ }^{\mathrm{b}}$, Nathalie Vergnolle ${ }^{\mathrm{a}, *}$

${ }^{a}$ Canadian Institutes of Health Research, Proteinases and Inflammation Network group, Dept. of Pharmacology and Therapeutics, University of Calgary, 3330 Hospital Drive, NW Calgary, Alberta, T2N4N1, Canada, ${ }^{b}$ Dept. of Surgery and Physiology, University of California San Francisco, San Francisco, USA, 'Neuro-Gastroenterology and Nutrition Unit, Institut National de la Recherche Agronomique, Toulouse, France, ${ }^{\mathrm{d} D e p t . ~ o f ~ D e r m a t o l o g y ~ a n d ~ L u d w i g ~ B o l t z m a n n ~ I n s t i t u t e ~ f o r ~ C e l l-~ a n d ~ I m m u n o b i o l o g y ~ o f ~}$ the Skin, University of Münster, Germany.

* Corresponding Author:

Dr. Nathalie Vergnolle

Dept. of Pharmacology and Therapeutics, Faculty of Medicine University of Calgary

3330 Hospital Drive NW Calgary, Alberta, T2N4N1, Canada

Tel: 14032204588

Fax: 14032108195

e-mail: nvergnol@ucalgary.ca 


\begin{abstract}
Proteinase-Activated Receptor-2 (PAR $)$ activation induces colonic inflammation by an unknown mechanism. We hypothesized that $\mathrm{PAR}_{2}$ agonists administered intracolonically in mice induce inflammation via a neurogenic mechanism. Pretreatment of mice with neurokinin-1/calcitonin-gene related peptide (CGRP) receptor antagonists or with capsaicin showed attenuated $\mathrm{PAR}_{2}$-agonist-induced colitis. Immunohistochemistry demonstrated a differential expression of type 1 CGRP receptor during the time-course of $\mathrm{PAR}_{2}$-agonist-induced colitis, confirming further, a role for CGRP. We conclude that $\mathrm{PAR}_{2}$ agonist-induced intestinal inflammation involves the release of neuropeptides, which by acting on their receptors, cause inflammation. These results implicate $\mathrm{PAR}_{2}$ as an important mediator of intestinal neurogenic inflammation.
\end{abstract}

Keywords: Trypsin; Proteinase-Activated Receptor-2; colitis; neurogenic inflammation; substance P; Neurokinin-1 receptors; Calcitonin-gene-related peptide.

\footnotetext{
Abbreviations: CGRP, calcitonin gene-related peptide; IBD, Inflammatory Bowel Disease; PAR, proteinase-activated receptor; $\mathrm{PAR}_{2}$, proteinase-activated receptor-2; PAR-AP, proteinase-activated receptor-activating peptide; $S P$, substance $P ; S L-\mathrm{NH}_{2}$, SLIGRL-NH,
} 


\section{Introduction}

Proteinase-Activated Receptors (PARs), comprise a family of four G protein-coupled receptors (PARs 1 to 4 ), that are activated by the proteolytic cleavage of their $\mathrm{N}$ terminal domain to unmask a tethered receptor-activating ligand (Vergnolle, Wallace et al., 2001). $\mathrm{PAR}_{1}, \mathrm{PAR}_{3}$ and $\mathrm{PAR}_{4}$, are targets for thrombin; $\mathrm{PAR}_{2}$ is activated by trypsin or human mast-cell tryptase. Proteolysis of the PARs by these and other serine proteinases at a target arginine can activate the receptors by revealing their tethered ligand (Vu et al., 1991; Coughlin, 1999; (Hollenberg and Compton, 2002). Of particular note is the ability of short synthetic peptides modeled on the sequence of the revealed tethered ligands to activate PARs 1,2 and 4 without the need for proteolysis ((Hollenberg and Compton, 2002); Vu et al., 1991). Pro-inflammatory properties have been described for peptide and enzyme agonists of the PAR family (Vergnolle, 2000;Vergnolle, Wallace, Bunnett, and Hollenberg, 2001). More specifically, PAR2 activation has been shown to induce edema, granulocyte infiltration, leukocyte rolling and adhesion in different tissues (Vergnolle, Hollenberg et al., 1999; Vergnolle, 1999;Schmidlin, Amadesi et al., 2002). Proteinases and in particular, trypsin and tryptase are elevated in the colon of Inflammatory Bowel Disease (IBD) patients (Bustos, Negri et al., 1998;Playford, Hanby et al., 1995;Raithel, Winterkamp et al., 2001; Tarlton, Whiting et al., 2000). Further, a signalling target for these two proteinases, $\mathrm{PAR}_{2}$ is also highly expressed in the gastro-intestinal tract (Cenac, Coelho et al., 2002; Vergnolle, 2000). In a previous study, we demonstrated that intra-colonic activation of $\mathrm{PAR}_{2}$ caused an inflammatory reaction characterized by an increase in wall thickness, infiltration of granulocytes, elevated $T$ helper cell type 1 cytokines, increased intestinal permeability and subsequent bacterial translocation 
(Cenac, Coelho, Nguyen, Compton, Andrade-Gordon, Macnaughton, Wallace, Hollenberg, Bunnett, Garcia-Villar, Bueno, and Vergnolle, 2002). However, the mechanism by which PAR2 activation causes colon inflammation is not yet known. PAR2 has been immunolocalized on rat primary sensory afferent neurons and its activation in isolated dorsal root ganglia neurons is known to cause the release of neuropeptides (Steinhoff, Vergnolle et al., 2000). In the gut, $\mathrm{PAR}_{2}$ has also been detected on enteric neurons (Cuffe, Bertog et al., 2002). However, the release of neurotransmitters via activation of enteric neuronal PARs has yet to be demonstrated directly. We hypothesized that $\mathrm{PAR}_{2}$ activation on enteric neurons causes the release of neurotransmitters; which then participate in the induction of intestinal inflammation. Here, we document that ablation of sensory nerves by capsaicin treatment completely abolishes $\mathrm{PAR}_{2}$ agonist-induced colonic inflammation. Furthermore, we show that Calcitonin Gene-Related Peptide (CGRP) and neurokin-1 (NK-1) receptors are involved in $\mathrm{PAR}_{2}$-induced colonic inflammation. These results reveal a proteinaseinduced neurogenic mechanism of inflammation in the gut, and highlight PAR2 as a potential target for the development of drugs for the treatment of intestinal inflammation with a neurogenic etiology.

\section{Methods}

\subsection{Chemicals}

Peptides (the selective PAR 2 -AP SLIGRL-NH ${ }_{2}$ and the control peptide LRGILS-NH inactive on $\mathrm{PAR}_{2}$ ), prepared by solid phase synthesis, were obtained from the peptide synthesis facility of the University of Calgary, Faculty of Medicine. The composition and the purity of peptides were confirmed by HPLC analysis and mass spectrometry. Peptides were dissolved in $10 \%$ ethanol, $10 \%$ Tween 80 and $80 \%$ saline $(\mathrm{NaCl} 0.9 \%)$. 
Trypsin from porcine pancreas (type IX, 16,700 units/mg of protein) was from Sigma (St-Louis, USA) and was diluted in saline. Capsaicin and CGRP ${ }_{8-37}$ were purchased from Sigma (St-Louis, USA).

\subsection{Treatments}

Animals were cared for in accordance with the Canadian Council on Animal Care.

All experimental protocols were approved by The University of Calgary Animal Care Committee. Mice obtained from Charles River laboratories (Quebec, Canada) and housed in a temperature-controlled room, were fasted for 12 hours before the beginning of experiments. Under light halothane anaesthesia, a polyethylene catheter was inserted intra-rectally, 3 to $4 \mathrm{~cm}$ from the anus, and PAR 2 -AP was administrated into the distal colon through the catheter, in a volume of $100 \mu \mathrm{l}$, as previously described (Cenac, Coelho, Nguyen, Compton, Andrade-Gordon, Macnaughton, Wallace, Hollenberg, Bunnett, Garcia-Villar, Bueno, and Vergnolle, 2002). Capsaicin (50 mg/kg, s.c.) or its vehicle ( $80 \%$ saline, $10 \%$ Ethanol, $10 \%$ Tween 80 ) were administered 7-days before the intra-colonic administration of $\mathrm{PAR}_{2}$ agonist, and the efficacy of capsaicin pre-treatment to ablate sensory nerves was tested just before the sacrifice of the animals, as previously described (Steinhoff, Vergnolle, Young, Tognetto, Amadesi, Ennes, Trevisani, Hollenberg, Wallace, Caughey, Mitchell, Williams, Geppetti, Mayer, and Bunnett, 2000). Pre-treatment with the CGRP receptor antagonist $\mathrm{CGRP}_{8-37}$ at a dose of $10 \mu \mathrm{g} / \mathrm{kg}$ (known to fully inhibit CGRP receptor activation (Keates, Castagliuolo et al., 1998)) or its vehicle (saline) was administered s.c. 1 hour before and 2 hours after the intra-colonic administration of the PAR 2 -AP. The neurokinin-1 receptor antagonist SR140333, kindly provided by Dr. Edmonds-Alt (Sanofi Recherches, Montpellier, France), was administered intraperitoneally (2 mg/kg 
in $0.1 \% \mathrm{DMSO}$ ), 1-hour before the intracolonic injection of the $\mathrm{PAR}_{2}-\mathrm{AP}$. This dose has previously been shown to fully inhibit NK-1 receptor activation (Amann, Schuligoi et al., 1995).

\subsection{Assessment of inflammation}

Inflammatory parameters were assessed 6-hours after the intracolonic administration of $\mathrm{PAR}_{2}$ agonists because it has been previously shown that $\mathrm{PAR}_{2}-\mathrm{AP}$-induced inflammation was maximal at this time-point (Cenac, Coelho et al., 2002). Mice were sacrificed by cervical dislocation, and distal colonic tissues were excised to assess macroscopic damage using criteria previously described (Cenac, Coelho, Nguyen, Compton, Andrade-Gordon, Macnaughton, Wallace, Hollenberg, Bunnett, GarciaVillar, Bueno, and Vergnolle, 2002). The bowel wall thickness was measured as an index of tissue edema, with a caliper at $1-\mathrm{cm}$ from the anus. Myeloperoxydase (MPO) activity, an index of tissue granulocyte infiltration, was assayed in tissues as described (Bradley, Priebat et al., 1982; Vergnolle, Comera et al., 1995).

\subsection{Immunohistochemistry}

Four, 6 and 10 hours after the intracolonic administration of peptides or their vehicle, anaesthetized mice were transcardially perfused and colonic tissues were collected, fixed and embedded as previously described (Cenac, Coelho, Nguyen, Compton, Andrade-Gordon, Macnaughton, Wallace, Hollenberg, Bunnett, Garcia-Villar, Bueno, and Vergnolle, 2002). Sections $(6 \mu \mathrm{m})$ were first washed for $10 \mathrm{~min}$. at room temperature? with neutral phosphate-buffered isotonic saline (PBS) containing $1 \%$ normal goat serum and $0.3 \%$ Triton $X-100$. After pre-blocking for 30 min with PBS containing $5 \%$ normal goat serum and $0.3 \%$ Triton $X-100$, sections were then incubated for 24 hours at $4^{\circ} \mathrm{C}$ with a 1:250 dilution of primary anti-rat RAMP-1 
antibody in PBS with 5\% normal goat serum and $0.3 \%$ Triton X-100 (rabbit antibody \#9891 from CURE/Digestive Diseases Research Center, Antibody/RIA Core),. In control experiments, primary antibody was replaced by blocking solution. Slides were washed and incubated with secondary antibody conjugated to fluorescein isothiocyanate (1:200 dilution; Jackson ImmunoResearch, West Grove, PA) for 2 hours at room temperature. Tissue sections were examined using an MRC 1000 laserscanning confocal microscope (Bio-Rad, Hercules, CA) equipped with krypton/argon laser and attached to a Zeiss Axiovert microscope. Images were processed using Adobe Photoshop.

\subsection{Data analysis}

For all groups, significance was estimated using the appropriate version of Student's $t$ test. Group data are expressed as mean \pm standard error, and a $p$ value less than 0.05 was required to reject the null hypothesis.

\section{Results}

3.1 Sensory nerve ablation inhibits $P A R_{2}-A P$-induced colitis.

Intraluminal injection of the PAR ${ }_{2}-\mathrm{AP}$ SLIGRL-NH $\mathrm{N}_{2}(100 \mu \mathrm{g} /$ mouse), but not the control peptide, LRGILS-NH $\mathrm{N}_{2}$, caused colonic inflammation characterized by mucosal damage, tissue edema and granulocyte infiltration (Figure 1 and (Cenac, Coelho, Nguyen, Compton, Andrade-Gordon, Macnaughton, Wallace, Hollenberg, Bunnett, Garcia-Villar, Bueno, and Vergnolle, 2002). Since PAR $-A P$-induced colon inflammation has been observed to be maximal 6-hours after the intra-colonic injection of $\mathrm{PAR}_{2}$ agonists (Cenac, Coelho, Nguyen, Compton, Andrade-Gordon, Macnaughton, Wallace, Hollenberg, Bunnett, Garcia-Villar, Bueno, and Vergnolle, 2002), the 6 hour time-point was selected for evaluation in all experiments examining 
the inflammatory effects of $\mathrm{PAR}_{2}$ agonists (peptides or enzymes). Pre-treatment of mice with the neurotoxin, capsaicin, completely abolished PAR $\mathrm{P}_{2}$-AP-induced increases in damage score (Figure $1 \mathrm{~A}$ ), wall thickness (Figure $1 \mathrm{~B}$ ) and MPO activity (Figure 1 C), compared with vehicle-treated mice. Capsaicin treatment also abolished trypsinand tryptase-induced mucosal damage, tissue edema and granulocyte infiltration (data not shown).

3.2 CGRP receptor activation is involved in PAR $-A P$-induced colitis.

Pre-treatment of mice with the CGRP antagonist $\mathrm{CGRP}_{8-37}$, completely abolished PAR $-A P$-induced mucosal damage (Figure $1 A$ ), reduced $P A R_{2}-A P$-induced increases in wall thickness by $93 \%$ (Figure 1B), but had no significant effect on granulocyte infiltration (Figure $1 C$ ). The involvement of the CGRP receptor in $\mathrm{PAR}_{2}$-AP-induced colitis was demonstrated further using an immunohistochemical approach. Immunolocalization of RAMP-1, a single membrane domain protein that interacts with the Calcitonin-Receptor-like receptor to form the type-1 CGRP receptor, was used as an index of CGRP receptor expression in the mouse colon. Immunoreactive RAMP-1 was detected at the plasma membrane of myenteric neurons, smooth muscle cells on muscle layers, and endothelial cells in the submucosa of mouse distal colon (Figure 2 A). Four hours after the colonic administration SLIGRL-NH $\mathrm{N}_{2}$ RAMP-1 immunoreactivity was markedly diminished in both intestinal layers (submucosa and muscle, see Figure 2 B) while at 6 (Figure $2 \mathrm{C}$ ) and 10 hours (data not shown), RAMP-1 was up-regulated in myenteric neurons, submucosal endothelium and smooth muscles. No RAMP-1 immunoreactivity was observed in tissues incubated with the blocking solution (Figure 2D). 


\subsection{Neurokinin-1 receptor activation is involved in $P A R_{2}-A P$-induced colitis.}

Compared with vehicle-treated animals, pre-treatment of mice with the NK-1 receptor antagonist SR 140333, at a dose that fully inhibited peripheral NK-1 receptor activation(Amann, Schuligoi, Holzer, and Donnerer, 1995), significantly reduced the $\mathrm{PAR}_{2}$-AP-induced inflammatory response as monitored by the damage score (Figure $1 \mathrm{~A}$ ), increased wall thickness (Figure $1 \mathrm{~B}$ ) and MPO activity (Figure $1 \mathrm{C}$ ). Damage, edema and granulocyte infiltration in mouse tissues were reduced by $71 \%, 40 \%$, and $61 \%$ respectively, 6-hours after the intra-colonic administration of the PAR $-A P$. Pretreatment with SR140333 also significantly inhibited trypsin- and human mast cell tryptase-induced damage score (by $86 \%$ and $76 \%$ respectively), increased in wall thickness (by $45 \%$ and $78 \%$ respectively) and increased MPO activity (by $81 \%$ and $75 \%$ respectively) (data not shown).

\section{Discussion}

We have previously shown that $\mathrm{PAR}_{2}$ agonists administered intra-colonically induce an acute inflammatory reaction, that reaches a maximum 6-hours after the intraluminal challenge (Cenac, Coelho et al., 2002). The main finding of the present study was that intestinal inflammation induced by either peptide or enzyme agonists of $\mathrm{PAR}_{2}$ was abrogated by the depletion of neurotransmitters in capsaicin-sensitive nerves and was attenuated by antagonists of neuropeptides (CGRP, neurokinins) that are released by such nerves.

The fact that $\mathrm{PAR}_{2}$ is present on enteric neurons (myenteric neurons and sensory afferents), where $\mathrm{PAR}_{2}$ activation could result in the release of substance $\mathrm{P}$ and CGRP, strongly suggests that in the mouse colon, direct activation of $\mathrm{PAR}_{2}$ on the 
enteric nervous system is responsible for the release of neuropeptides, which in turn cause responses (increased permeability, leukocyte recruitment) that are hallmarks of inflammation. All of the indices of the $\mathrm{PAR}_{2}$ agonist-induced inflammatory reaction (damage score, edema, granulocyte infiltration) were completely abolished by sensory nerve ablation, suggesting further that direct activation of capsaicin-sensitive neurons plays a predominant role in $\mathrm{PAR}_{2}$ agonist-induced colitis. However, in the gut, $\mathrm{PAR}_{2}$ is also present in other cell types (such as enterocytes, smooth muscle cells, fibroblasts), and one cannot rule out the possibility that other PAR $\mathrm{P}_{\mathbf{2}}$-expressing cells might also be involved in the induction of PAR2 colitis.

The results with the receptor antagonists provide further evidence that CGRP and neurokinin-releasing sensory nerves are involved in $\mathrm{PAR}_{2}$ agonist-induced colitis. The down-regulation (4-h time-point, see Figure 2B) followed by elevated expression (6and 10-h time-points, see Figure 2C) of RAMP-1, a marker of the CGRP type I receptor, supports further the hypothesis that CGRP release is a key factor in the pathophysiology of the changes observed after luminal exposure to $\mathrm{PAR}_{2}$ agonists. Although treatment with the NK-1 antagonist, SR140333, significantly inhibited all the hallmarks of inflammation induced by $\mathrm{PAR}_{2}$ activation, we were not able to detect by immunohistochemistry, differential expression or clear internalization of the NK-1 receptor at the same time-points (data not shown). This result might suggest that NK1 receptors are playing a less important role than are CGRP receptors in $\mathrm{PAR}_{2}$ agonist-induced colitis. However, the results obtained with the receptor antagonists provided a different perspective. Whilst NK-1 receptor antagonist treatment was able to inhibit the increase in MPO activity significantly (Figure $1 \mathrm{C}$ ), CGRP receptor antagonist treatment had no significant effect on increases in MPO activity (Figure 
1C). Conversely, the CGRP receptor antagonist completely inhibited $\mathrm{PAR}_{2}$ agonistinduced increase in the damage score, whereas the NK-1 receptor antagonist only partially inhibited damage. These results suggest complementary roles for CGRP and NK-1 receptors in $\mathrm{PAR}_{2}$ agonist-induced colitis. Both receptors seem to be involved in the generation of edema. Activation of the CGRP receptor appears to be a crucial component for the induction of $\mathrm{PAR}_{2}$ agonist-induced macroscopic damage score, whereas CGRP receptor activation seems to play only a minor role in the recruitment of granulocytes to the inflammatory site. In contrast, NK-1 receptor activation is actively involved in granulocyte recruitment process. It is thus possible that activation and internalization of NK-1 receptor in mouse after intra-colonic administration of a $\mathrm{PAR}_{2}$ agonist occurs at time-points different than the ones we evaluated $(4,6$ and 10 h).

The present study also supports the hypothesis that trypsin and mast cell tryptase are potential candidates for activating $\mathrm{PAR}_{2}$ in the course of colonic inflammation. We have found in previous work (Cenac, Coelho, Nguyen, Compton, Andrade-Gordon, Macnaughton, Wallace, Hollenberg, Bunnett, Garcia-Villar, Bueno, and Vergnolle, 2002) that trypsin and human mast cell tryptase, which enzymes are both elevated in the colon of inflammatory bowel disease patients, can cause colitis similar to that induced by $\mathrm{PAR}_{2}-\mathrm{APs}$. Here we show that like $\mathrm{PAR}_{2}-\mathrm{AP}$-induced colitis, trypsin and human mast cell tryptase-induced colitis is also mediated by the activation of capsaicin-sensitive sensory nerves, and by the activation of NK-1 receptors.

Although trypsin and mast cell tryptase appear to be the best endogenous candidates for activating $\mathrm{PAR}_{2}$ in the human gut lumen, it is possible that other serine proteinases with "trypsin-like" activity, will also be found to activate $\mathrm{PAR}_{2}$ in the colonic lumen. 
Such proteinases could include not only endogenous enzymes but also pathogenderived serine proteinases. It has been shown, for instance, that a bacterial proteinase derived from Porphyromonas gingivalis is able to activate $\mathrm{PAR}_{2}$ (Lourbakos, Potempa et al., 2001). Enteric nerves are known to play a key role in the intestinal response to intestinal infections, by orchestrating an immediate inflammatory response (Spiller, 2002). It can be hypothesized that the activation of $\mathrm{PAR}_{2}$ by pathogen-derived proteinases or by endogenously-released proteinases, could play a crucial role in enteric infections, leading to the primary inflammatory response. In that setting, inhibition of $\mathrm{PAR}_{2}$ activation could represent an attractive therapeutic intervention in the course of enteric infections.

In summary, our study shows that activation of capsaicin-sensitive sensory nerves and the subsequent activation of neuropeptide receptors like those for neurokinins and CGRP can play a crucial role in $\mathrm{PAR}_{2}$ agonists-induced colitis. The present results therefore implicate $\mathrm{PAR}_{2}$ as an important mediator of intestinal neurogenic inflammation. 
Figure 1: Modulation of $\mathrm{PAR}_{2}$-AP-induced inflammation by capsaicin (caps.), CGRP receptor antagonist $\left(\mathrm{CGRP}_{8-37}\right), \mathrm{NK}-1$ receptor antagonist (SR for SR140333) or their respective vehicle pre-treatment in C57BI6 mice. Macroscopic damage score (A), wall thickness (B) and MPO activity (C) were evaluated as inflammatory parameters, 6 hours after the intracolonic injection of saline or $100 \mu \mathrm{g}$ per mouse of the $\mathrm{PAR}_{2}-\mathrm{AP}$ SLIGRL-NH $\mathrm{N}_{2}$ or the control peptide LRGILS-NH . Values are mean \pm S.E.M., $\mathrm{n}=8$ per group, * significantly different from vehicle-treated group, $p<0.05$.
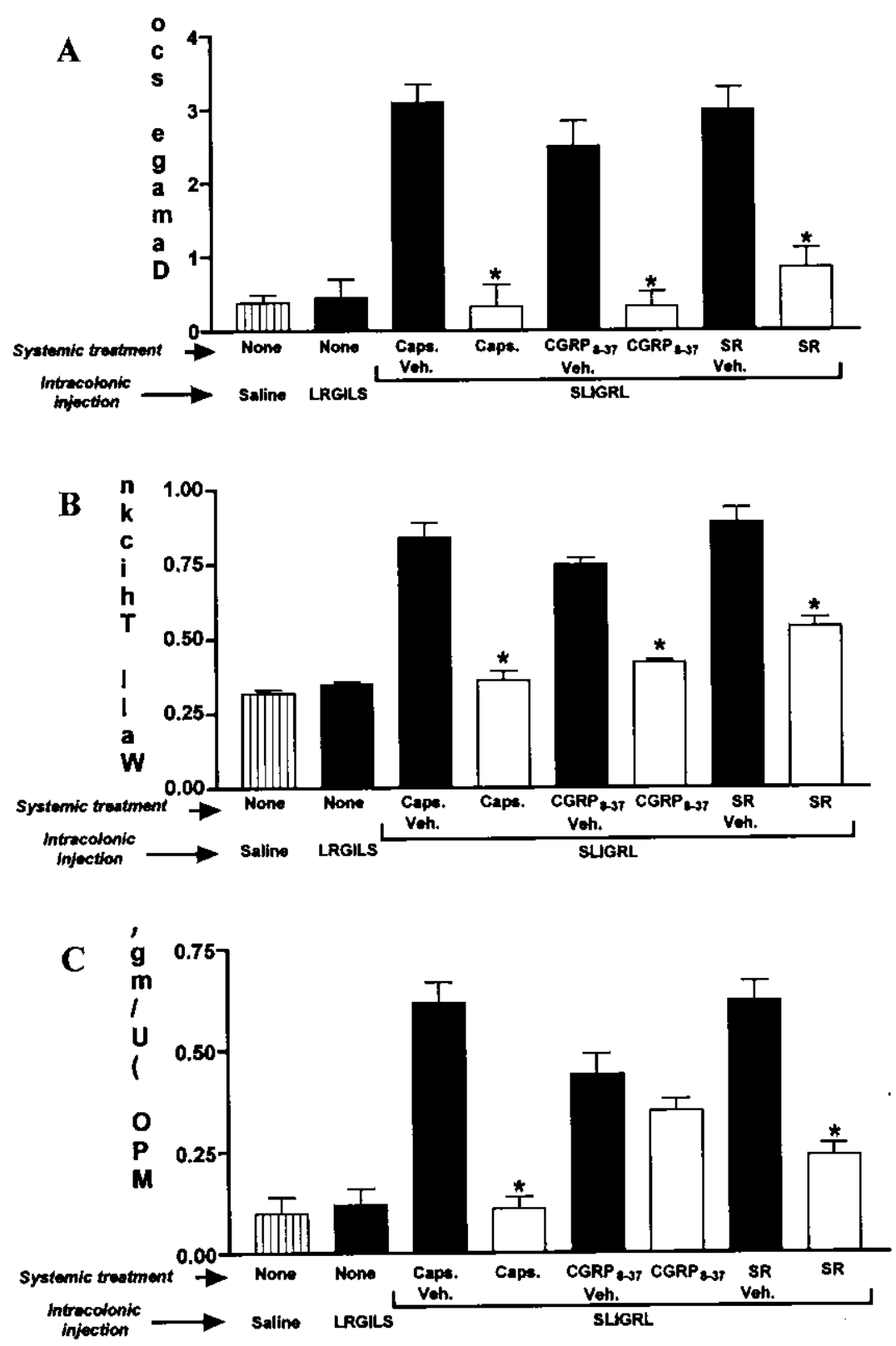
Figure 2: Confocal micrographs showing immunolocalization of RAMP-1 in tissue section of mouse distal colon, after intracolonic administration of PAR2-AP SLIGRL$\mathrm{NH}_{2}(100 \mu \mathrm{g} /$ mouse $)$ or vehicle. Tissues were collected at various time after intracolonic administration of vehicle (veh.) or SLIGRL-NH ${ }_{2}$ (SL-NH $)$. RAMP-1 was localized using a RAMP-1 antiserum \#9891 (1:250, 24 hours, $4^{\circ} \mathrm{C}$ ). The control (con.) shows omission of primary antibody. Arrowheads, endothelial cells; arrow, muscle cells and enteric neurons. $s m$, submucosa; $c m$, circular muscle. Images are composites of 5 to 10 sections of $0.5 \mu \mathrm{m}$. Scale bar, $10 \mu \mathrm{m}$.

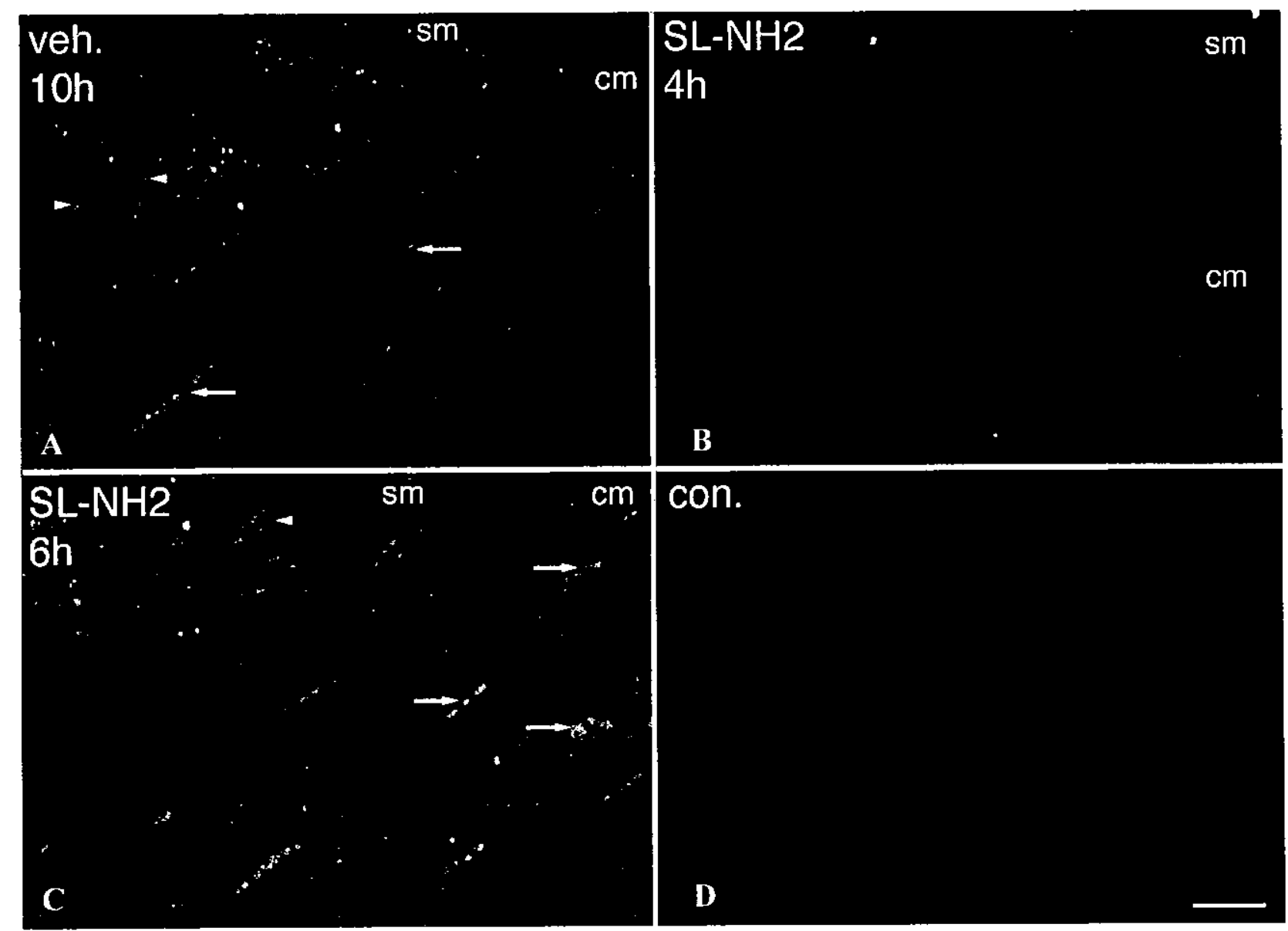




\section{Reference List}

1. Amann,R., Schuligoi,R., Holzer,P., Donnerer,J., 1995. The non-peptide NK1 receptor antagonist SR140333 produces long-lasting inhibition of neurogenic inflammation, but does not influence acute c. Naunyn Schmiedebergs Arch.Pharmacol. 352, 201-205.

2. Bradley,P.P., Priebat,D.A., Christensen,R.D., Rothstein,G., 1982. Measurement of cutaneous inflammation: estimation of neutrophil content with an enzyme marker. J.Invest Dermatol. 78, 206-209.

3. Bustos,D., Negri,G., De Paula,J.A., Di Carlo,M., Yapur,V., Facente,A., De Paula,A., 1998. Colonic proteinases: increased activity in patients with ulcerative colitis. Medicina (B Aires) 58, 262-264.

4. Cenac,N., Coelho,A., Nguyen,C., Compton,S., Andrade-Gordon,P., Macnaughton,W.K., Wallace,J.L., Hollenberg,M.D., Bunnett,N.W., GarciaVillar,R., Bueno,L., Vergnolle,N., 2002. Induction of intestinal inflammation in mouse by activation of Proteinase-Activated Receptor-2. Am.J Pathol. 161, 19031915.

5. Cuffe,J.E., Bertog,M., Velazquez-Rocha,S., Dery,O., Bunnett,N., Korbmacher,C., 2002. Basolateral PAR-2 receptors mediate $\mathrm{KCl}$ secretion and inhibition of $\mathrm{Na}(+)$ absorption in the mouse distal colon. J Physiol 539, 209-222.

6. Hollenberg,M.D., Compton,S.J., 2002. International Union of Pharmacology. XXVIII. Proteinase-activated receptors. Pharmacol.Rev. 54, 203-217. 
receptor 2 induce inflammation by a neurogenic mechanism. Nat Med 6, 151158

14. Tarlfon,J.F., Whiting,CV., Tunmore,D., Bregenholt,S., Rèmann,J.,

13. Glaesson M.H, Bland,PW 2000 . The role of up-regulated serine proteases and matrix metalloproteinases in the pathogenesis of a murine moderof colitis Am.J Rathol 157, 1927-1935.

15. Vergnolle,N., 1999. Proteinase-activated receptor-2-activating peptides induce leukocyte rolling, adhesion, and extravasation in vivo. J Immunol 163, 50645069.

16. Vergnolle,N., 2000. Review article: proteinase-activated receptors-novel signals for gastrointestinal pathophysiology. Aliment.Pharmacol:Ther: 14, 257-266.

17. Vergnolle,N., Comera,C., Bueno,L., 1995. Annexin 1 is overexpressed and specifically secreted during experimentally induced colitis in rats. Eur J Biochem $232,603-610$.

18. Vergnolle,N., Hollenberg,M.D., Sharkey,K., Wallace,J.L., 1999. Characterization of the inflammatory response to proteinase-activated receptor-2 (PAR-2)activating peptides in the rat paw. $\mathrm{Br} \mathrm{J}$ Pharmacol 127, 1083-1090.

19. Vergnolle,N., Wallace,J.L., Bunnett,N.W., Hollenberg,M.D., 2001. Proteaseactivated receptors in inflammation, neuronal signaling and pain. Trends Pharmacol.Sci. 22, 146-152. 